\title{
UM ESTUDO SOBRE A EDUCAÇÃO DO SUJEITO SURDO NA REDE ESTADUAL DE EDUCAÇÃO DE FOZ DO IGUAÇU - PARANÁ.
}

\author{
J. S. ANGNES', N. A. B. MORÁS, M. L. KLOZOVSKI, K. M. REALI \\ Universidade Estadual do Centro Oeste do Paraná (UNICENTRO) \\ julianeangnes@gmail.com*
}

Artigo submetido em 08/03/2017 e aceito em 07/11/2016

DOI: $10.15628 /$ holos. 2016.4248

\section{RESUMO}

Este estudo realizado a partir de uma revisão bibliográfica e entrevista semiestruturada com gestores e alunos surdos de três colégios inclusivos da cidade de Foz do Iguaçu, propõe discutir sobre Política Nacional de Educação Especial na Perspectiva da Educação Inclusiva (Brasil, 2008), que preconiza a garantia do direito à educação se efetiva por meio do acesso a educação inclusiva em todos os níveis. Com o objetivo de contribuir, com a comunidade surda e seus anseios de fazer valer sua cultura e identidade, elegeu-se como foco de estudo a inclusão escolar de surdos na cidade de Foz do Iguaçu. Ou seja, pesquisar como ocorre a inclusão escolar destes sujeitos, hoje, em Foz do Iguaçu e se esta proporciona uma educação de boa qualidade permitirá dar visibilidade a realidade local a partir de uma política nacional. Adota-se como pressuposto que o
\end{abstract}

gestor escolar possui um papel fundamental neste contexto. Isto quer dizer que se acredita que seja por meio da gestão de uma escola que se inicia o exemplo em ser educar de forma ética e com princípios democráticos, em que todos os alunos possam ter subsídios para formarem-se enquanto cidadãos críticos dotados de valores voltados à coletividade. Os dados obtidos no decorrer da pesquisa apontaram que apesar da luta constante da comunidade surda pelo respeito e aceitação como grupo cultural distinto, ainda há uma dificuldade muito grande de desenvolvimento da inclusão dos surdos com base no respeito a suas diferenças.

PALAVRAS-CHAVE: Sujeito Surdo, Inclusão, Gestores e Políticas Públicas.

\section{A STUDY ON THE EDUCATION OF THE DEAF IN THE SUBJECT STATE NETWORK FOZ DE IGUAÇU EDUCATION - PARANÁ.}

\begin{abstract}
This study from a literature review and interview in a question and answer with managers and deaf students from three colleges inclusive city of Foz do Iguaçu, discuss proposed National Policy on Special Education in the Perspective of Inclusive Education (Brazil, 2008) which states that the guarantee of the right to education is realized through access to inclusive education at all levels. Aiming to contribute, just by knowing and working as a teacher with the deaf community and their desires to assert their culture and identity, was elected as the focus of study inclusion of deaf school in the city of Foz do Iguaçu. le search occurs as school inclusion of these subjects today in Foz do Iguaçu and this provides a quality education will give visibility to local reality from a national policy. The
\end{abstract}

adopted assumption that the school management has a key role in this context. This means that it is believed that it is through the management of a school that starts the example to be educating ethically and with democratic principles in which all students can have grants to graduate-while citizens with critical values directed to the community. The data obtained during the research lead us to believe that despite the constant struggle of the deaf community through respect and acceptance as a distinct cultural group, there is a great difficulty of developing the inclusion of deaf people based on respect for their differences.

KEYWORDS:Deaf subject, Inclusion, Managers and Public Policy. 


\section{INTRODUÇÃO}

A educação inclusiva é um fato imposto em muitos países, inclusive no Brasil; entretanto, historicamente tem havido fracasso na educação de surdos. Especificamente, no que diz respeito ao acesso das pessoas surdas à escola regular, acredita-se que, para haver o processo de inclusão escolar, torna-se necessária uma transformação do sistema de ensino que venha a beneficiar toda e qualquer pessoa levando em conta a especificidade do sujeito e não mais suas deficiências e limitações.

Compreender que a forma como se olha para a surdez implica em uma diferença na forma como se trabalha com a educação dos surdos é o primeiro passo para o desenvolvimento de um projeto sobre a inclusão destes. Por isso, ao se entender a surdez exclusivamente sob o ponto de vista biológico, implica pensá-la com uma falta, portanto, considera-se o aluno surdo deficiente. Entretanto, sob o ponto de vista antropológico, a surdez é concebida também como uma diferença cultural, ou seja, trata-se de um grupo com uma língua e cultura específica, e é nesta perspectiva que este estudo se insere.

A concepção sócio-antropológica parte do princípio de que os surdos formam comunidades linguísticas minoritárias que compartilham uma Língua de Sinais e valores culturais, hábitos e modos de socialização próprios cujo fator aglutinante é a Língua de Sinais. Leva-se em consideração o grau da perda auditiva, mas não se busca a cura da surdez. São as relações sociais e culturais que constituem os sujeitos, e é isso que precisa ser trazido também para o seu ensino escolar.

Assim, o "outro - aquele que é diferente de mim - é produzido a partir daquilo que falamos sobre ele. $\mathrm{O}$ que falo, os nomes dos outros e os enquadramentos que ocupam, são formas de identificação que eles carregam - são identidades" (Lopes, 2007, p.23).

Nesse sentido, a relevância em deixar evidente qual o posicionamento em relação à surdez, de onde ela é "olhada", como pensar e reproduzir o olhar sobre ela relaciona-se intimamente à constituição da identidade dos surdos. Concorda-se com Perlin quando destaca a identidade surda: "surdo tem diferença e, não deficiência" (2010, p. 56). Ou seja, os surdos não se entendem como deficientes, embora eles possam ser constituídos assim em circunstâncias nas quais a audição e a fala oral sejam pautadas como normalidade.

Esta concepção está em consonância com a definição atual de surdez, de acordo com o Decreto $n^{\circ} 5626 / 2005^{1}$ que considera a pessoa surda aquela que, por ter perda auditiva, compreende e interage com o mundo por meio de experiências visuais, manifestando sua cultura principalmente pelo uso da Língua Brasileira de Sinais-Libras. De acordo com esse documento, a surdez precisa ser reconhecida pelas suas características culturais manifestadas especialmente por meio de sua língua materna.

A Política Nacional de Educação Especial na Perspectiva da Educação Inclusiva orienta o processo de inclusão para as pessoas com necessidades educacionais especiais e, no caso de alunos surdos, propõe a educação bilíngue como diretriz político-pedagógica, na qual a LIBRAS seja a língua de instrução e a Língua Portuguesa, na sua modalidade escrita, a língua ensinada com metodologia de ensino de segunda língua.

${ }^{1} O$ Decreto $n^{\circ} 5626 / 2005$ refere-se a regulamentação que dispõe sobre a Língua Brasileira de Sinais. 
Dessa forma, o documento garante o espaço de escolaridade de pessoas surdas em escolas e classes de educação bilíngue, salvaguardando a singularidade linguística desses alunos, bem como a presença de tradutores/intérpretes de LIBRAS/Língua Portuguesa. Esta é a situação política atual, ou seja, há um posicionamento oficial de que a melhor proposta educacional para o aluno surdo é a educação bilíngue.

Torna-se relevante destacar que esta pesquisa não é contra ou a favor da inclusão dos surdos em escolas regulares, pois parte-se do pressuposto teórico de que esta já deixou de ser uma opção, é uma constante realidade que precisa ser repensada e trabalhada.

Em outras palavras, a escolha do tema se justifica porque se acompanhou dois momentos relevantes de lutas e conquistas dos surdos, e esses momentos levaram a motivação desta pesquisa. O primeiro momento foi à passagem do oralismo para bilinguismo, no qual os surdos por anos lutaram para reconhecimento de sua língua, LIBRAS - Língua Brasileira de Sinais que passou a ser reconhecida pela Lei Nacional no 10.436, de 24 de abril de 2002, e o segundo momento foi a criação da Política Nacional de Educação Especial na Perspectiva da Educação Inclusiva (BRASIL, 2008), que preconiza que a garantia do direito à educação se efetiva por meio do acesso à educação inclusiva em todos os níveis.

Dessa maneira, justamente por conhecer e trabalhar-se com a comunidade surda e seus anseios de fazer valer sua cultura e identidade, elegeu-se como foco de estudo a inclusão escolar de surdos na cidade de Foz do Iguaçu. Ou seja, pesquisar como ocorre a inclusão escolar desses sujeitos hoje em Foz do Iguaçu e se a escola proporciona uma educação de boa qualidade permitirá dar visibilidade para a realidade local a partir de uma política nacional.

Por isso, adota-se como pressuposto que o gestor escolar possui um papel fundamental neste contexto. Isto quer dizer que se acredita que seja por meio da gestão de uma escola que se inicia o exemplo em se educar de forma ética e com princípios democráticos, em que todos os alunos possam ter subsídios para formarem-se enquanto cidadãos críticos dotados de valores voltados à coletividade.

Para tanto, esta pesquisa propõe as seguintes indagações: Como os gestores escolares e os alunos surdos dos colégios inclusivos de Foz do Iguaçu se posicionam em relação à aprendizagem significativa proposta pela política nacional de educação especial na perspectiva da educação inclusiva? Há inclusão na prática? Quais as dificuldades encontradas nesse processo?

Para dar conta desses questionamentos ou dessas perguntas de pesquisa, este estudo efetua uma análise de fragmentos de falas dos gestores e alunos surdos, apresentadas em respostas a uma entrevista semiestruturada para três gestores e quinze alunos surdos, procurando descrever se os colégios estaduais de Foz do Iguaçu que oferecem educação inclusiva para surdos estão realmente proporcionando uma boa educação bilíngue para os mesmos.

Neste ínterim, os objetivos específicos foram delimitados da seguinte maneira: a) compreender se ambiente educacional é recomendado para aquisição de conhecimento científico e o desenvolvimento da sua primeira língua, cumprindo as determinações das leis, diretrizes e decretos em vigor; b) discutir se as metodologias de trabalho contemplam cultura e identidade do surdo por meio de atividades eavaliações diferenciadas; c) descrever as principais dificuldades da inclusão de alunos surdos no ensino regular nas escolas foco da pesquisa. 


\section{QUEM É O SUJEITO SURDO?}

A compreensão da surdez como deficiência ou diferença depende do conceito teórico observado. Os dois construtos mais latentes e observados são: clínico-terapêutico e sócioantropológico. Na concepção clínica-terapêutica, impôs uma visão estritamente relacionada com a patologia, com o déficit biológico, se traduziu educativamente em estratégias e recursos de índole reparadora e corretiva. (Lopes, 2007)

Existe um momento na história em que as crianças foram tiradas da escola, do âmbito pedagógico e obrigadas a transitar pelo domínio da medicina, de acordo com um processo que alguns autores chamam a medicalização da surdez. Medicalizar a surdez significava "procurar a cura do problema auditivo, à correção do defeito da fala, o treinamento como leitura labial entre outros". (Skilar, 1999, p. 25)

A surdez era vista como uma deficiência. Uma doença que precisava de cura, tendo o oralismo o parâmetro de normalidade, esses sistemas causaram maiores confusões nas mensagens linguísticas, menores possibilidades de acesso à informação, e, sobretudo, se transformam em verdadeiros obstáculos para que as crianças surdas adquiram a língua de sinais de sua comunidade. (Skilar, 1999)

A partir de certo momento percebe-se a necessidade de um novo modelo explicativo sobre a surdez, um no qual a surdez não seja vista somente como um déficit a ser curado, mas um modelo em que se origine e se justifique nas interações normais e habituais dos surdos entre si, no qual a língua de sinais seja respeitada e tida como veículo fundamental desenvolvimento linguístico e cognitivo do surdo e o modelo pedagógico não seja uma obsessão para corrigir o déficit ou falta.

A visão sócio-antropológica da surdez, que tem em Skliar $(1997,1998,1999)$ o seu principal difusor, apresenta uma ideologia diferente da visão clínica, pois aborda o paradigma social, cultural e antropológico da surdez e aprofunda os conceitos de bilíngue e bicultural. $O$ modelo bilíngue prioriza o acesso a duas línguas: a primeira língua - a Língua de Sinais -, utilizada na comunicação entre os pares e no acesso ao desenvolvimento global na medida em que é percebida como uma verdadeira língua, e a segunda língua - língua oral ou escrita -, como meio de integração à sociedade ouvinte. Partindo do acesso das duas línguas, o sujeito desenvolve-se inserido numa rede bicultural (cultura surda e ouvinte).

Neste sentido, cabe salientar que junto com a língua distinta dos surdos, tem uma cultura, ou seja, junto ao bilinguismo, temos o biculturalismo, revendo antes um processo ignorado, que é o processo de construção de identidade cultural surda, uma vez que o surdo tem contato com dois grupos culturais distintos, o do ouvinte e o do surdo. Portanto, é relevante que em seu contexto educacional o aluno surdo tenha experiências culturais de sua comunidade surda, a fim de que tenha um desenvolvimento significativo e uma ratificação de sua identidade surda na escola.

A lei de LIBRAS n.o 10.436/2002 foi regulamentada, no Brasil, pelo Decreto 5626/2005, que traz no seu artigo 2. uma definição de pessoa surda, como sendo aquela que, por ter perda auditiva, compreende e interage com o mundo por meio de experiências visuais, manifestando sua cultura principalmente pelo uso da Língua de Sinais - LIBRAS.

A questão incide em levantar os interrogantes que levaram as histórias, culturas e identidades surdas a assumirem uma relação subordinada na configuração escolar existente 
(Lunardi, 1998). Parte-se do pressuposto que a linguagem tem consequências importantes para a questão da diferença e da identidade cultural. No caso dos surdos faz-se relevante compreendêlos pela perspectiva antropológica segundo a qual os mesmos têm possibilidades diferentes e não menores que as dos ouvintes.

Hall (1997) denomina, no seu "circuito de cultura", a cultura como sendo significados e identidades compartilhados. A identidade é construída na e por meio da língua. Ou seja, os surdos constroem sua identidade por meio de experiências visuais, deixando claro que o papel no desenvolvimento da pessoa surda, vincula-se diretamente ao respeito a diferença, uma vez que essa diferença gera a necessidade de um processo educativo singular.

No caso dos surdos, a diferença é aquilo que o outro é e que eu não sou, já que à medida que se afirma ser surdo, se está automaticamente, negando a condição de ouvinte, por exemplo. Com isso, a identidade não pode ser compreendida como um processo natural, mas, um processo cultural em constante movimento.

Conforme Vygotsky (1993) "não é a surdez que define o destino das pessoas, mas o resultado do olhar da sociedade sobre a surdez" (p. 45). A teoria Vygotkyana enfatiza que o professor precisa estar preparado para atender o desenvolvimento dos seus alunos, o ritmo de aprendizagem de cada um e ter clareza de que o papel do docente é educar e desenvolver a todos.

\subsection{O processo de aprendizagem do surdo: como ocorre?}

A aprendizagem e o desenvolvimento acontecem ocorrem por meio da interação social. Goldfeld (1997) afirma que uma das maiores contribuições de Vygostky é a ideia de que a aprendizagem impulsiona o desenvolvimento. De acordo com a autora, "a aprendizagem e o desenvolvimento, então, estão inter-relacionados desde os primeiros dias de vida da criança. A aprendizagem está sempre um pouco à frente, proporcionando o desenvolvimento" (1997, p. 70).

De acordo com a teoria sócio-interacionista de Vygotsky (1993) a aprendizagem está intimamente relacionada com a interação social. Segundo Oliveira (1997) a aprendizagem pode ser definida como “... o processo pelo qual o indivíduo adquire informações, habilidades, atitudes, valores, etc. a partir de seu contato com a realidade, o meio ambiente, as outras pessoas" (p. 57).

Dessa forma, entende-se que a aprendizagem tenha estreita relação com a linguagem, pois é por meio dessa que ocorre a mediação entre o sujeito aprendente e o mundo. A aquisição da linguagem, de acordo com Vygotsky (1993), dá-se a partir das relações interpessoais, no sentido do meio social para o indivíduo. Assim, o meio social, linguístico e cultural, em que a criança vive, é essencial para o seu desenvolvimento e aprendizagem. Desse modo, de acordo com Goldfeld (1997, p. 71) “... por um atraso de linguagem a criança tem seu aprendizado escolar e, consequentemente, seu desenvolvimento afetado".

A surdez, nessa perspectiva, é vista como diferença cultural e política e essa é a visão que acreditamos ser importante aos pais. É essencial que eles vejam seus filhos como integrantes de uma cultura, que não é melhor nem pior que a deles, mas diferente, por ser composta por pessoas surdas, que se comunicam através da língua de sinais e que pertencem à cultura surda. 
Respeitar a diferença não pode significar "deixar que o outro seja como eu sou" ou "deixar que o outro seja diferente de mim tal como eu sou diferente (do outro)", mas deixar que o outro seja como eu não sou, deixar que ele seja esse outro que não pode ser eu, que eu não posso ser, que não pode ser um (outro) eu; significa deixar que o outro seja diferente, deixar ser uma diferença que não seja, em absoluto, diferença entre duas identidades, mas diferença da identidade, deixar ser uma outridade que não é outra "relativamente a mim" ou "relativamente ao mesmo", mas que é absolutamente diferente, sem relação alguma com a identidade ou com a mesmidade (Pardo apud Silva, 2000, p. 101).

A inclusão na educação de surdos é aquela que parte da diferença e possibilita o acesso aos conteúdos pela língua de sinais, língua própria da cultura surda; que propicia a exposição e discussão de ideias por meio da sua língua e, a partir disso, constitui também a identidade surda desses sujeitos.

De acordo com a teoria sóciointeracionista, a aprendizagem acontece por meio da interação social e esta só pode acontecer quando as partes se comunicam por meio de uma língua expressada e compreendida. É através da linguagem e da interação que as pessoas se desenvolvem. A linguagem é um instrumento de pensamento. A língua é uma forma de linguagem. A língua de sinais é a língua própria dos surdos. Ela surgiu a partir da necessidade dos surdos de se comunicarem e é passada de geração em geração, por meio do contato entre pessoas surdas usuárias desta língua. Quanto mais cedo houver o contato entre pessoas surdas usuárias da língua de sinais, melhor será a aquisição dessa língua pela criança surda e, consequentemente, melhor será o seu desenvolvimento e aprendizagem.

\subsection{A Inclusão: fatores relevantes}

Consta-se que a inclusão das pessoas surdas possa acontecer no momento em que estes sujeitos tenham possibilidade de se comunicarem com suas famílias através da língua de sinais, possam aprender através dessa língua, tenham contato com seus pares e estejam inseridos na sua própria cultura.

Neste contexto, pensar a inclusão de surdos nas escolas regulares, com a declaração de Salamanca (Brasil, 1994) decorre a política educacional "inclusiva" que, na verdade, trouxe para os sujeitos surdos a inversão da vida comunicativa: incluir para excluir do processo educativo. A declaração faz menção à situação linguística dos surdos e defende escolas e classes para eles (Artigo 21 , p. 30). O problema é que os governantes não respeitam essa ressalva e tratam os surdos como os demais alunos.

É imprescindível que essas discussões sejam levantas ao se pensar uma proposta de educação para todos por meio da Escola Inclusiva, tão evocada nas atuais políticas educacionais brasileiras. Negar as múltiplas identidades, como também, os espaços de fronteiras no interior das práticas e das políticas educacionais, é continuar a representar cultura e identidade em termos estáticos e a-teóricos. Pensar a escola a partir de uma perspectiva das culturas híbridas não se refere a um processo tranquilo de integração de diferenças, mas de um espaço de lutas e constantes ressignificações. Essa reorganização dos cenários culturais e os cruzamentos constantes das identidades exigem dos educadores e pesquisadores do campo da educação investigar de outro modo as ordens que sintetizam as relações materiais e simbólicas entre os grupos (Conclini, 1998). 
Vale salientar que a modalidade da "diferença" se fundamenta na subjetivação cultural. Ela surge no momento em que os surdos atingem sua identidade, por meio da diferença cultural que surge no pós-colonial. Nesse espaço, "não mais se dá a sujeição ao que é do ouvinte, não ocorre mais a hibridização, ocorre à aprendizagem nativa do próprio surdo" (Strobel; Perlin, 2008, p. 18).

Dessa forma, de acordo com Strobel e Perlin (2008), torna-se crucial que haja a possibilidade dos surdos ascenderem a uma educação que contemple sua própria cultura em uma mediação intercultural (surda e ouvinte), com o propósito de contribuir para a desconstrução dos preconceitos e da discriminação em relação a eles, que passarão a ser perspectivados por sua diferença surda. Para a efetivação desse ideal, deve estar claro que o currículo escolar necessita conter não apenas os elementos temáticos da cultura surda, mas ser organizado dentro da perspectiva visual de aprendizagem dos mesmos.

Se os gestores não repensarem a construção e adequação do currículo para a real inclusão do aluno surdo no ensino regular, seguindo os ideais de participação e mudança, o fracasso desse aluno será grande e permanente, principalmente quando alcançar um determinado grau de escolaridade e perceber que está sozinho e isolado dentro da sala de aula e da escola. Portanto, a construção adequada de um currículo pensado e organizado para atender as necessidades e dificuldades do aluno surdo; com a participação de seus representantes, como intérprete de LIBRAS, e o aprendizado da língua de sinais por todos os agentes da escola; é de suma importância para proporcionar a ele, aluno surdo, a sua participação efetiva e qualitativa na "educação para todos" segundo a LDB (Brasil, 1996) e vivenciar a verdadeira inclusão.

Assim, sobre o currículo, enfatiza-se a necessidade de que este, a partir da perspectiva intercultural, contemple os conhecimentos legítimos da cultura ouvinte e da surda, tal qual afirma uma aluna surda, em depoimento a Andreis-Witkoski (2012b, p. 94) "currículo surdo precisa contemplar história do surdo, identidade, cultura, língua, tudo dentro do currículo, igual o ouvinte, precisa ter dentro o que é do surdo".

O currículo deve ser construído e/ou reelaborado considerando as especificidades do aluno surdo. A esse respeito, em sua dissertação, Pedroso $(2001$, p. 25) afirma que:

A construção de um currículo para surdos, que contemple as suas necessidades, a sua forma de comunicação e a sua cultura, é essencial na busca de um modelo de ensino apropriado para esses alunos, com qualidade, de fato, e capaz de promover a sua educação, na plenitude, ou seja, formá-lo e informá-lo, garantindo-Ihe autonomia diante das circunstâncias às quais está exposto, na sua vida individual e social.

Nesse sentido, a inclusão só daria resultados positivos se fosse além dos direitos iguais e alcançasse o respeito à diferença. Caso esse respeito à diferença não exista, dar-se-á margem ao processo de exclusão, uma vez que esse aluno surdo, dentro de uma sala de aula com vinte ou trinta alunos ouvintes, não irá acompanhar os colegas em face da ausência de atenção especial para sua singularidade.

Neste caso, o ideal sobre a inclusão nas escolas de ouvintes, é que as mesmas se preparem para dar aos alunos surdos os conteúdos pela língua de sinais, por meio de recursos visuais, tais como figuras, língua portuguesa escrita e leitura, a fim de desenvolver nos alunos a memória visual e o hábito de leitura. 
Também se torna relevante que recebam apoio de professor especialista conhecedor de língua de sinais e, enfim, proporcionando intérpretes de língua de sinais, para o maior acompanhamento das aulas. Outra possibilidade é contar com a ajuda de professores, instrutores e monitores surdos, que auxiliem o professor e trabalhem com a língua de sinais nas escolas. Concordando com a afirmação, Skliar (1998, p. 37) afirma que:

\begin{abstract}
Nesse sentido, a escola democrática é aquela que se prepara para atender cada um de seus alunos. Se ela não tem condições de fazer esse atendimento, o professor precisa entrar em contato com os órgãos competentes e discutir o tema. Como responsável por vários cursos de libras e de intérpretes, entende-se que a formação de professores para atender a alunos surdos depende da convivência com a comunidade surda, a aprendizagem da língua de sinais e o estudo de uma pedagogia ampla.
\end{abstract}

Considera-se importante ressaltar que a dificuldade de formação de professores constitui um desafio não somente entre os ouvintes, que precisam adentrar a cultura surda, conhecer profundamente as características do processo visual de aprendizagem dos alunos surdos e tornarem-se fluentes nas Libras, mas também para professores surdos, como afirma aluna surda de uma dos colégios inclusivos de Foz do Iguaçu (Entrevista 1A): "...complicado porque os professores não respeitam surdos e não espera, sabem que surdos tem dificuldade em português escrito...". Para a efetivação desse ideal, deve estar claro que o currículo escolar necessita conter não apenas os elementos temáticos da cultura surda, mas ser organizado dentro da perspectiva visual de aprendizagem dos mesmos.

\title{
3 METODOLOGIA
}

A pesquisa realizada foi exploratória e teve como objetivo aumentar o conhecimento do conteúdo estudado, por meio de literaturas de cunho científico e informativo e entrevistas com os gestores escolares e os alunos surdos dos colégios inclusivos de Foz do Iguaçu para averiguar como se posicionam em relação à aprendizagem significativa proposta pela política nacional de educação especial na perspectiva da educação inclusiva. Além disso, buscou verificar se há inclusão na prática e quais as dificuldades encontradas nesse processo. Através disso, elaborar possível sugestão para melhoria da prática educativa.

Segundo Gil (2002, p. 41), a pesquisa exploratória tem como "proporcionar maior familiaridade com o problema, com vistas a torná-lo mais explícito ou construir hipóteses", sendo o seu planejamento bastante flexível e, na maioria dos casos, envolve levantamento bibliográfico, aplicação de questionários e entrevistas com pessoas envolvidas com o problema pesquisado e análise de exemplos que estimulem a compreensão.

A pesquisa que se relata neste artigo é classificada como qualitativa, (Denzin; Lincoln, 2006) por considerar a abordagem qualitativa como construtivista, considerando o mundo social como representação, cuja ênfase está nas qualidades das entidades sobre os processos e os significados como um conhecimento indutivo. A pesquisa qualitativa dá ênfase aos processos sociais e seus significados, em que a realidade pesquisada é socialmente construída. No lugar de pressupor uma relação de exterioridade ontológica entre sujeito e objeto, a pesquisa qualitativa localiza o pesquisador no mundo. Dessa forma, as verdades são construídas levando em 
consideração o tempo e espaço em que os discentes estão inseridos. A compreensão destes sentidos socialmente construídos é elaborada a partir de uma grande diversidade.

Assim, neste estudo foram pesquisados três colégios estaduais da cidade de Foz do Iguaçu, no mês de junho de 2014, um que oferece ensino fundamental para séries finais e ensino médio, um que oferece ensino técnico magistério e um que oferece ensino de jovens e adultos. Nesse contexto, foram entrevistados quinze alunos surdos e três gestores.

Os registros foram provenientes da entrevista realizada em forma de perguntas e respostas, para depois realizar a análise. Primeiramente entregou-se para cada gestor entrevistado uma folha contendo nove perguntas versando sobre os eixos: escola inclusiva, processo de inclusão, papel do gestor e do professor neste processo. Estas entrevistas foram realizadas no período de seis a dez de junho de 2015.

Por sua vez, para o aluno surdo, entregou-se a entrevista contendo oito questões versando sobre as seguintes questões: como é uma escola inclusiva, papel do gestor e do professor neste processo. Estas entrevistas foram realizadas no período de quatro a dez de junho de 2015.

Por medidas éticas as citações dessas respostas serão mencionadas no decorrer do artigo como (Entrevista $1 \mathrm{G}$ ) referindo-se ao gestor 1, (Entrevista $2 \mathrm{G}$ ) referindo-se gestor 2 e (Entrevista $3 \mathrm{G}$ ) referindo-se gestor 3, já para fala dos alunos (Entrevista 1 A) referindo-se aluno 1, (Entrevista $2 \mathrm{~A}$ ) referindo-se aluno 2 e assim até aluno número 15, mantendo assim o anonimato dos colaboradores do nosso trabalho. Logo após as entrevistas passou-se a leitura cuidadosa e atenta dos registros escritos. A partir dessa organização, realizou-se uma análise dos fragmentos de seus discursos.

\section{ANÁLISE DOS RESULTADOS}

\subsection{Perfil dos Entrevistados}

A história dos surdos na cidade de Foz do Iguaçu se confunde com a história da APASFI (Associação de Pais e Amigos dos Surdos de Foz do Iguaçu) tem seu início no ano de 1979, quando Lucimar Gonçalves, a primeira aluna surda é matriculada no Colégio Estadual Bartolomeu Mitre tendo por diretora a Sra. Eva Terezinha Vera que preocupada em dar atendimento especializado a alunos surdos e aos outros surdos que também haviam se matriculado, pede ajuda ao coronel Clovis Cunha Viana (prefeito da cidade) e colaboradores da comunidade que custearam a viagem dos alunos a Cascavel, onde estes realizaram exames audiométrico.

A educação inclusiva dos alunos surdos na cidade de Foz do Iguaçu iniciou-se no ano de 1999, e o Colégio Estadual Bartolomeu Mitre foi pioneiro nesta conquista da comunidade surda. Neste mesmo ano o Colégio Barão do Rio Branco ofereceu inclusão para curso técnico de magistério. Nos anos posteriores ampliados para mais um colégio estadual que oferece educação para Jovens e adultos - CEEBJA. Desde então os surdos tem acessibilidade nos colégios estaduais com a presença de intérpretes contratados pelo poder público. Hoje os três colégios citados anteriormente atendem aproximadamente 40 alunos surdos matriculados do 6. ano ao 9. ano, ensino médio, técnico magistério e educação jovens e adultos (Apasfi, 2002).

Os gestores envolvidos são professores de quadro próprio do magistério do estado do Paraná, que foram eleitos por votação entre professores, pais e alunos do colégio, estão na 
direção dos colégios por dois anos. Os alunos são surdos que estudam nestes colégios num ensino inclusivo com a presença de intérpretes. Quatro dos alunos entrevistados são do ensino fundamental séries finais com idade entre 13 e 15 anos, nove estudam no ensino médio com idade entre 15 a 18 anos e dois que estudam no ensino de jovens e adultos com idades de 18 a 22 anos. Todos os alunos são filhos de pais ouvintes e quase a totalidade dos alunos são provenientes de famílias de baixa renda.

\subsection{O que dizem os gestores e os alunos surdos sobre a educação inclusiva?}

Ao tratar da escolarização dos surdos importa, inicialmente, destacar que tais sujeitos fazem parte de uma população que, por muitos anos, permaneceu à parte do convívio social, ou quando muito, limitado no âmbito do assistencialismo ou da filantropia quase sempre amparada pelo olhar médico. Ao pensar a inclusão com o reconhecimento da diferença, surge a necessidade de uma discussão a respeito do processo de inclusão, sendo que esta se vincula diretamente à forma como se dá o processo e o respeito ao surdo durante o processo de inclusão.

Nesse sentido, a inclusão só daria resultados positivos se fosse além dos direitos iguais e alcançasse o respeito à diferença. Caso esse respeito à diferença não exista, dar-se-á margem ao processo de exclusão, uma vez que esse aluno surdo, dentro de uma sala de aula com vinte ou trinta alunos ouvintes, não irá acompanhar os colegas em face da ausência de atenção especial para sua singularidade.

Neste sentido, percebeu-se nas entrevistas realizadas com gestores dos três colégios inclusivos de Foz do Iguaçu que ainda o olhar sobre a surdez de dois deles é pensada sobre o ponto de vista biológico, ou seja, quando se perguntou quem é o sujeito surdo os mesmos respondem:

Ele é uma pessoa normal, porém com deficiência auditiva (Entrevista $1 \mathrm{G}$ ).

Aluno surdo é um jovem/adolescente em idade escolar, com necessidades especiais (Entrevista $2 \mathrm{G}$ ).

Em apenas um dos colégios o gestor afirmou:

É um sujeito de direitos que deve ser respeitado na sua diversidade, particularidade e integridade (Entrevista $3 \mathrm{G}$ ).

Por sua vez, os alunos surdos responderam:

Ser capaz, com uma língua diferente (Entrevista 1 A).

Tem vontade de aprender experiências e ser feliz (Entrevista 2 A). 
Tal perspectiva deixa claro que para a inclusão escolar dos sujeitos surdos aconteça faz-se necessária à aproximação do conhecimento e dos discursos sobre surdez no território dos estudos surdos em educação, buscando desconstruir o olhar sustentado no senso da deficiência para pensar-se sobre outros aspectos que envolvam a surdez como diferença cultural.

Neste sentido, concorda-se com Perlin quando afirma "surdo tem diferença e, não, deficiência" (2010, p. 56). Este posicionamento fica expresso em uma das respostas escritas por uma aluna entrevistada:

A diferença de surdo é que não ouve nos somos todos iguais, capazes (Entrevista 2 A).

Observa-se que nesta resposta o surdo é visto muitas vezes como "menos capaz" que o ouvinte, o que segundo ela não se sustenta, pois "somos tão capazes como os ouvintes" (Entrevista $3 \mathrm{~A}$ ). Parte-se do pressuposto que se os educadores não se atentarem para esta perspectiva, a inclusão pode fracassar, uma vez que não proporciona melhor desenvolvimento educacional e emocional ao sujeito surdo, mas, sim, um estigma de deficiente que tem que lutar para ser igual ao ouvinte, que seria o modelo ideal.

Em complemento, ao perguntar sobre o que faz uma escola ser inclusiva, para as alunas surdas entrevistadas, ela escreve:

Que respeite as diferenças e dificuldades dos surdos, em português... redação, verbo, poesia, etc" (Entrevista $1 \mathrm{~A}$ ).

Perante esse depoimento, percebe-se que o enfoque dado, quando se remete à educação do surdo, a questão do desenvolvimento da criança surda vincula-se diretamente ao respeito à diferença, uma vez que essa diferença gera a necessidade de um processo educativo singular. Diante desse fato, tal questão envolve também um processo político, na medida em que essa diferença resulta em situações de desvantagem numa cultura hegemonicamente ouvinte.

Já quando realizada a mesma questão aos gestores obteve-se as seguintes respostas:

Dar possibilidade ao incluso de algo a mais (Entrevista $1 \mathrm{G}$ ).

Uma escola inclusiva vinha atender a(s) necessidade(s) grupos sem nenhum tipo de distinção (Entrevista $2 \mathrm{G}$ ).

A escola é inclusiva quando dá conta de atender o aluno surdo na sua especificidade, considerando não só pedagogicamente, mas também socialmente (Entrevista $3 \mathrm{G}$ ).

As preocupações explicitadas fazem com que se considere o papel do professor no processo de inclusão, pois é ele que vai viabilizar na sala de aula as condições adequadas para atender a todos os alunos em suas necessidades e peculiaridades e, mais do que isso, contribuir para o seu desenvolvimento a fim de que possam participar, efetivamente, em todas as instâncias de convívio social. 
Neste sentido, os gestores foram explícitos em suas respostas. Ou seja, quando perguntados sobre o papel do professor na inclusão escolar do aluno surdo, disseram que há deficiência de formação para está área, que estão atentos, pois o:

Professor tem objetivo principal trabalhar conhecimento, mas sua prática não se restringe a isso. Há outros fatores que ele deve pensar, entre eles a inclusão (Entrevista $2 \mathrm{G}$ ).

Um dos gestores coloca que o professor deve:

Estar atento ao planejamento, avaliação e encaminhamento que atenda as condições dos surdos (Entrevista $3 \mathrm{G}$ ).

Esse entendimento é sustentado na teoria Vygotskyana, que enfatiza que o professor deve ser preparado para atender o desenvolvimento dos alunos, o ritmo de aprendizagem de cada um e com a clareza do seu papel de educar e desenvolver a todos.

Skliar, cujos trabalhos na área da surdez têm sido uma referência no Brasil, ao tratar da formação do professor, ressalta a dimensão política dessa formação. Política compreendida como relação de poder e conhecimento que deve estar contemplada, não só na proposta pedagógica, mas além dela. Ele propõe uma ruptura com o modelo vigente caracterizado "como positivista a-histórico e despolitizado" (Skliar, 1997, p.7) e defende uma ressignificação da escola como espaço de fronteira e onde diferentes identidades possam conviver.

Ele considera relevante que a formação do professor para a educação de surdos, em relação a uma escola inclusiva, tenha, em primeiro lugar, os significados políticos que circulam sobre a surdez e os surdos presentes nas escolas. Considera, também, a "questão da língua dos sinais, as identidades, a comunidade, a cultura e o acesso dos surdos às segundas línguas" (Skliar, 2000, p. 162).

Desta forma, ao realizar-se a questão no que se refere ao currículo no contexto escolar inclusivo os gestores, afirmaram que:

Se considerarmos o currículo como todos aquelas práticas que a escola desenvolve para que o aluno aprenda e desenvolva habilidades e conhecimentos há muito a se avançar. Os livros didáticos, currículos não contemplam na sua essência as necessidades dos surdos. A Língua de Sinais é uma barreira porque os professores, familiares, pedagogos e funcionários não a dominam. Práticas como avaliações diferenciadas devem ser melhoradas. Livros, jornais, material pedagógicos devem ser preparados para essas necessidades (Entrevista $2 \mathrm{G}$ ).

Por sua vez, o segundo gestor respondeu:

Busca reconhecer, no entanto se coloca muitas vezes um currículo dos alunos/ouvintes, sem se preocupar em desenvolver a linguagem de sinais/LIBRAS de forma curricular (Entrevista $3 \mathrm{G}$ ). 
Vale ressaltar que no que se refere ao fragmento de discurso apresentando pelo gestor, faz-se necessário explicitar que não é linguagem de sinais, mas sim, LIBRAS - Língua Brasileira de Sinais.

O terceiro disse:

Sim, porém nem todos os currículos são aplicados ao pé da letra. Justamente por isso, acredita-se que a proposição do currículo deve caminhar em direção de uma teoria que melhor dê conta das complexidades individuais e coletivas dos alunos surdos na perspectiva inclusivista. Defende-se neste posicionamento, a necessidade da formação do professor, tanto inicial como continuada, lembrando, no entanto, que o mesmo não deve ser preparado para atendimento clínico ou terapêutico dos seus alunos, mas para lidar pedagogicamente com eles. (Entrevista $1 \mathrm{G}$ ).

Parte-se do pressuposto que as escolas que não têm o perfil da especificidade podem também realizar um excelente trabalho, caso queiram. Gestores deixam claro também ao perguntar se a inclusão de surdos funciona de verdade em seu colégio, relatam:

Funciona, não sei bem se é de verdade (Entrevista $1 \mathrm{G}$ ).

Não. Seria uma mentira afirmar que sim. As vezes me pergunto: qual escola contempla a inclusão na sua essência? é o mesmo principio de achar que a democracia existe. Ela não existe (Entrevista $2 \mathrm{G}$ ).

Buscamos incluir cada aluno, de acordo com sua particularidade, fazendo com que funcione da melhor forma possível a inclusão in loco (Entrevista $3 \mathrm{G}$ ).

Em contraponto, os alunos responderam:

Não, os professores nunca se organizam para ensinar os surdos, nunca pensam no seu desenvolvimento (Entrevista $3 \mathrm{~A}$ ).

Inclusive, uma das alunas relata uma situação considerada grave e triste:

Não, a professora explica uma matéria para todos, não deixa surdo fazer igual, ela troca para surdos a matéria fácil e para ouvintes matéria normal (Entrevista 4 A).

Neste sentido, aos serem questionados, alunos e gestores, sobre que tipo de ação poderia ser sugerida no sentido de tornar eficaz a inclusão do aluno surdo na escola regular, os alunos surdos escreveram: 
Necessário melhor comunicação (Entrevista 2 A).

Por sua vez, os gestores relataram:

Capacitação da equipe de professores, agentes educacionais e a aceitação por ambos (Entrevista $1 \mathrm{G}$ )

Acredito que uma das primeiras ações é dominarmos a LIBRAS (Entrevista $2 \mathrm{G}$ ).

Contratar intérpretes de LIBRAS de forma antecipada (Entrevista $3 \mathrm{G}$ ).

O que se defende, em outras palavras, é a necessidade de formar profissionais que acolham o novo, presente em cada aluno surdo, livre de preconceito e comprometido politicamente com a função cultural e social de produzir sentido, de construir conhecimentos e reconhecer a plenitude do desenvolvimento desses sujeitos a despeito de suas diferenças.

Pode-se concluir que o sucesso da inclusão escolar dos surdos dependerá da hierarquia das línguas envolvidas, dos objetivos educacionais, da formação adequada e continuada dos professores, da arquitetura educacional, das trocas com o contorno social, da consideração quanto aos contextos psicossociais e culturais, do comprometimento dos estudantes, dentre outros fatores. O ideal sobre a inclusão nas escolas de ouvintes, é que as mesmas se preparem para dar aos alunos surdos os conteúdos pela língua de sinais, através de recursos visuais, tais como figuras, língua portuguesa escrita e leitura, a fim de desenvolver nos alunos a memória visual e o hábito de leitura; que recebam o apoio de professor especialista conhecedor de língua de sinais e enfim, proporcionando intérpretes de língua de sinais, para o maior acompanhamento das aulas. Outra possibilidade é contar com a ajuda de professores, instrutores e monitores surdos, que auxiliem o professor e trabalhem com a língua de sinais nas escolas (Strobel, 2006).

\section{CONSIDERAÇÕES FINAIS}

A cultura e a comunidade surda, por se tratarem de dimensões inseridas na cultura hegemônica, que é a ouvinte, foram e são formadas, ainda hoje, com base na exclusão imposta pelo mundo ouvinte, como também com base nos valores negativos propostos a essa diferença. A cultura surda começou a expandir-se não somente no âmbito educacional, ou seja, não mais como uma língua diferente, mas também por conhecimentos e crenças comuns que auxiliaram na constituição de uma cultura própria. Então, a constituição da identidade dos surdos passa pela mudança de paradigma da deficiência para o de minoria linguística e cultural.

Conviver com aqueles que compartilham uma condição funcional acaba, assim, fortalecendo os processos identitários que têm marcado essas novas configurações do movimento de surdos, sendo algo de fundamental importância para o reconhecimento social da cultura surda.

Apesar da luta constante da comunidade surda pelo respeito e aceitação como grupo cultural distinto, ainda há uma dificuldade muito grande de desenvolvimento da inclusão dos surdos com base no respeito a suas diferenças. Há que se considerar, por exemplo, que a maioria das crianças surdas são filhos de pais ouvintes, o que, em seu desenvolvimento, proporciona maiores dificuldades, dado que essa condição leva à presença de rupturas no processo de comunicação entre pais e filho surdo. Tais rupturas, por sua vez, acarretam, às vezes, problemas 
de ordem social e cognitiva cuja expressão é muito mais o resultado da incapacidade dos ouvintes em assumir formas de comunicação e intervenção que considerem as particularidades da surdez do que devido a dificuldades inerentes à ausência de audição. Partindo disso, é fundamental que instituições escolares, os pais, enfim, os grupos ou comunidades interrelacionadas que rodeiam a criança surda, preocupem-se em entender o modo pelo qual ela se comunica para que as trocas possam existir de forma satisfatória para ambas as partes.

É preciso eliminar do percurso que os surdos foram submetidos, ou seja, é necessário, para um adequado desenvolvimento tanto físico quanto psíquico, que a cultura hegemônica deixe de ser considerado o modelo de perfeição e passe a perceber que o pluralismo não significa inferioridade. Com esse novo olhar, não seria mais preciso que o sujeito surdo sofresse um atraso em seu desenvolvimento em decorrência da adequação ao modelo hegemônico.

A condição funcional dos sujeitos é parte constituinte não só de sua identidade mas também de como esse processo atua nas formas de organização política e social de um grupo minoritário. Logo, ressalta-se a importância do reconhecimento da diferença não como algo de menor valor em relação ao que é compartilhado pelos grupos hegemônicos, mas, sim, como algo intrínseco e singular do sujeito, pois é com base nessa diferença que o surdo se constitui.

Assim, a formação do educador, que tem como preocupação essas questões, deve compreender a história dos sujeitos surdos, as restrições sociais e familiares e escolares a que sempre foram submetidos, os nexos políticos com a sociedade e as formas de constituição do saber escolar, resgatando a educação como um bem social e instrumento para sair-se da condição marginal e fundamentada no "direito de todos" terem acesso a um ensino de qualidade.

O que defendo, em outras palavras, é a necessidade de formar profissionais que acolham o novo, presente em cada aluno surdo, livre de preconceito e comprometido politicamente com a função cultural e social de produzir sentido, de construir conhecimentos e reconhecer a plenitude do desenvolvimento desses sujeitos a despeito de suas diferenças.

\section{REFERÊNCIAS}

Andreis-Witkoski, S. (2012b). Educação de surdos e preconceito. Curitiba: CRV.

Apasfi. (2002). APASFI - Há 20 anos, promovendo a cidadania dos Surdos de Foz do Iguaçu. Foz do Iguaçu. Ano 01 - Edição no 01, dezembro.

Brasil (2008). Ministério da Educação. Política Pública de Educação Especial na Perspectiva da Educação Inclusiva. Disponível em: http://portal.mec.gov.br/arquivos/pdf/politicaeducespecial.pdf.

Brasil. (2005). Decreto no 5.626, de 22 de dezembro de 2005. Regulamenta a Lei no 10.436, de 24 de abril de 2002, que dispõe sobre a Língua Brasileira de Sinais - Libras, e o art. 18 da Lei no 10.098, de 19 de dezembro 2000. Disponível em: http://www.planalto.gov.br/ccivil_03/_ato2004-2006/2005/decreto/d5626.htm

Brasil. (2002) Lei no 10.436, de 24 de abril de 2002. Dispõe sobre a Língua Brasileira de Sinais Libras e dá outras providências. Disponível em: http://www.planalto.gov.br/ccivil_03/leis/2002/I10436.htm

Brasil. (1988) Constituição Federal Brasileira. Brasília. 
Brasil. (1996). Lei no 9.394/96. Diretrizes e Bases da Educação Nacional. Brasília: MEC.

Brasil. (1994). Ministério da Educação. Secretaria de Educação Especial. Política Nacional de Educação Especial. Brasília: MEC/SEESP.

Carvalho, A. P. (2012). Políticas de Educação Especial no Ensino Médio Público Paranaense: o aluno com deficiência em foco. Dissertação (mestrado em educação). PPGE/UFPR. Curitiba.

Conclini, N. G. (1998). Culturas híbridas: estratégias para entrar e sair da modernidade. São Paulo: Editora da Universidade de São Paulo.

Denzin, N. K.; Lincoln, Y. S. (2006). Planejamento da pesquisa qualitativa: teorias e abordagens. Porto Alegre: Artmed.

Fernandes, S. (2007). Educação de Surdos. Curitiba: IBPEX.

Gil, A. C. (2002). Como elaborar projetos de pesquisa. 4. ed. São Paulo: Atlas.

Goldfeld, M. (1997). A criança surda: linguagem e cognição numa perspectiva sóciointeracionista. São Paulo: Plexus.

Hall. S. A. (1997). Centralidade da cultura: notas sobre as revoluções culturais do nosso tempo. Porto Alegre.

Lopes, M. (2007). Inclusão escolar, currículo, diferença e identidade. In: LOPES, M. C.; Dal'igna, M. C. (Orgs.). In/Exclusão: nas tramas de escola. Canoas: Editora da Ulbra, p. 11-33.

Lunardi, M. L. (1998). Educação de surdos e currículo: um campo de lutas e conflitos. 1998. Dissertação (Mestrado). Universidade Federal do Rio Grande do Sul, Faculdade de Educação, Programa de Pós-graduação em Educação, Porto Alegre.

Oliveira, M. K. (1997). Vygotsky: aprendizado e desenvolvimento: um desenvolvimento sóciohistórico. São Paulo: Scipione.

Paraná. (2013). SUED/SEED. Instrução 02/2008. Estabelece critérios para o funcionamento do Centro de Atendimento Especializado na Área da Surdez - CAES, serviço de apoio especializado, no ensino regular. Disponível em: http://www.educacao.pr.gov.br/modules/conteudo/conteudo.php?conteudo=151Acesso em 09 de julho.

Paraná. (2003). Secretaria de Educação. Deliberação N.ㅇ 02/03. Dispõe sobre as Normas para a Educação Especial, modalidade da Educação Básica para alunos com necessidades educacionais especiais, no Sistema de Ensino do Estado do Paraná. Curitiba.

Pedroso, C. C. A.(2001). Com a palavra o surdo: aspectos do seu processo de escolarização. 2001. 155f. Dissertação (Mestrado em Educação) - Universidade Federal de São Carlos. São Carlos, SP.

Perlin, G. T. (2010). Identidades surdas. In: Skliar, C. (Org.). A Surdez: um olhar sobre as diferenças. 4. ed. Porto Alegre: Mediação. p. 51-73.

Silva, T. T. da (Org). (2000). Identidade e diferença: a perspectiva dos estudos culturais. Petrópolis: Ed. Vozes.

Skliar. C. B. A. (2000). Formação de professores (surdos e ouvintes) desde a perspectivada diferença. In: ENCONTRO NACIONAL DE PROFESSORES DE DIDÁTICA E PRÁTICA DE ENSINO, 10. 2000. Rio de Janeiro, Anais. Rio de Janeiro: UERJ. 
Skliar, C. B. (Org.). (1999). Atualidade da educação bilíngue para surdos. Porto Alegre: Mediação, v. 1-2.

Skliar, C. B. (1998). A forma visual de entender o mundo. In: Educação para todos. Revista especial, SEED/DEE. Curitiba: Editora Expediente.

Skliar, C. B (Org.) (1997). Educação e exclusão: abordagem sócio-antropológica da educação especial. Porto Alegre: Média.

StrobeL, K. (2009). As imagens do outro sobre a cultura surda. 2ed. rev. Florianópolis: Ed. da UFSC.

Strobel, K. L.; Perlin, G. (2013). Fundamentos da educação de surdos. Universidade Federal de Santa Catarina. Licenciatura em Letras/Língua Brasileira de Sinais, 2008. Disponível em: <http://www.scribd.com/doc/4559884/Fundamentos-da-Educacao--dos-surdos>. Acesso em: 10 jun.

Vygotsky, L. S. (1993). A formação social da mente: o desenvolvimento dos processos psicológicos superiores. São Paulo: Martins Fontes. 